\title{
CORRECTION
}

View Article Online

View Journal I View Issue

W) Check for updates

Cite this: RSC Adv., 2021, 11, 18615

DOI: 10.1039/d1ra90119b

rsc.li/rsc-advances

\section{Correction: Development and in vitro evaluation of $\kappa$-carrageenan based polymeric hybrid nanocomposite scaffolds for bone tissue engineering}

\author{
Muhammad Umar Aslam Khan, ${ }^{\text {abc }}$ Mohsin Ali Raza, ${ }^{c}$ Hassan Mehboob, ${ }^{d}$

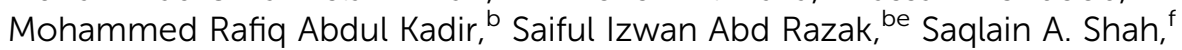 \\ Muhammad Zahir lqbal ${ }^{9}$ and Rashid Amin*h \\ Correction for 'Development and in vitro evaluation of $\kappa$-carrageenan based polymeric hybrid \\ nanocomposite scaffolds for bone tissue engineering' by Muhammad Umar Aslam Khan et al., RSC Adv., \\ 2020, 10, 40529-40542. DOI: 10.1039/D0RA07446B.
}

The authors regret errors in Fig. 9 in the original article. The corrected Fig. 9 is shown below where all three +ive control panels and the 72 h CG-g-Aac-2 panel have been replaced.

\footnotetext{
${ }^{a}$ Department of Polymer Engineering and Technology, University of the Punjab, 54590 Lahore, Pakistan. E-mail: umaroo7khan@gmail.com ${ }^{b}$ School of Biomedical Engineering and Health Sciences, Faculty of Engineering, Universiti Teknologi Malaysia, 81300 Skudai, Johor, Malaysia 'Department of Metallurgy and Materials Engineering, CEET, University of the Punjab, Lahore, Pakistan ${ }^{d}$ Department of Engineering Management, College of Engineering, Prince Sultan University, P. O. Box No. 66833, Rafha Street, Riyadh 11586, Saudi Arabia ${ }^{e}$ Center for Advanced Composite Materials, Universiti Teknologi Malaysia, 81300 Skudai, Johor, Malaysia ${ }^{f}$ Materials Science Lab, Department of Physics, Forman Christian College (University), Lahore, Pakistan ${ }^{g}$ Nanotechnology Research Laboratory, Faculty of Engineering Sciences, GIK Institute of Engineering Sciences and Technology, Topi 23640, Khyber Pakhtunkhwa, Pakistan ${ }^{h}$ Department of Biology, College of Sciences, University of Hafr Al Batin, 39524 Hafar Al-batin, Saudi Arabia. E-mail: rashida@uhb.edu.sa
} 

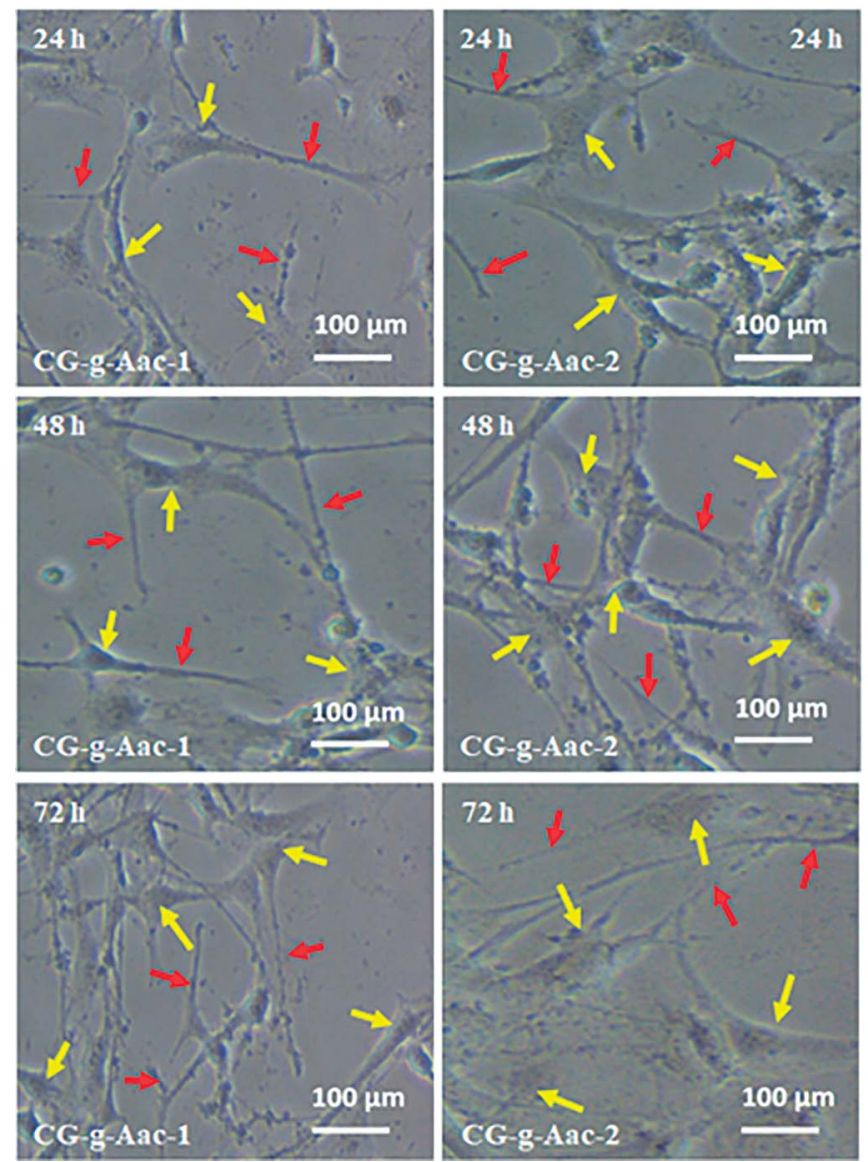
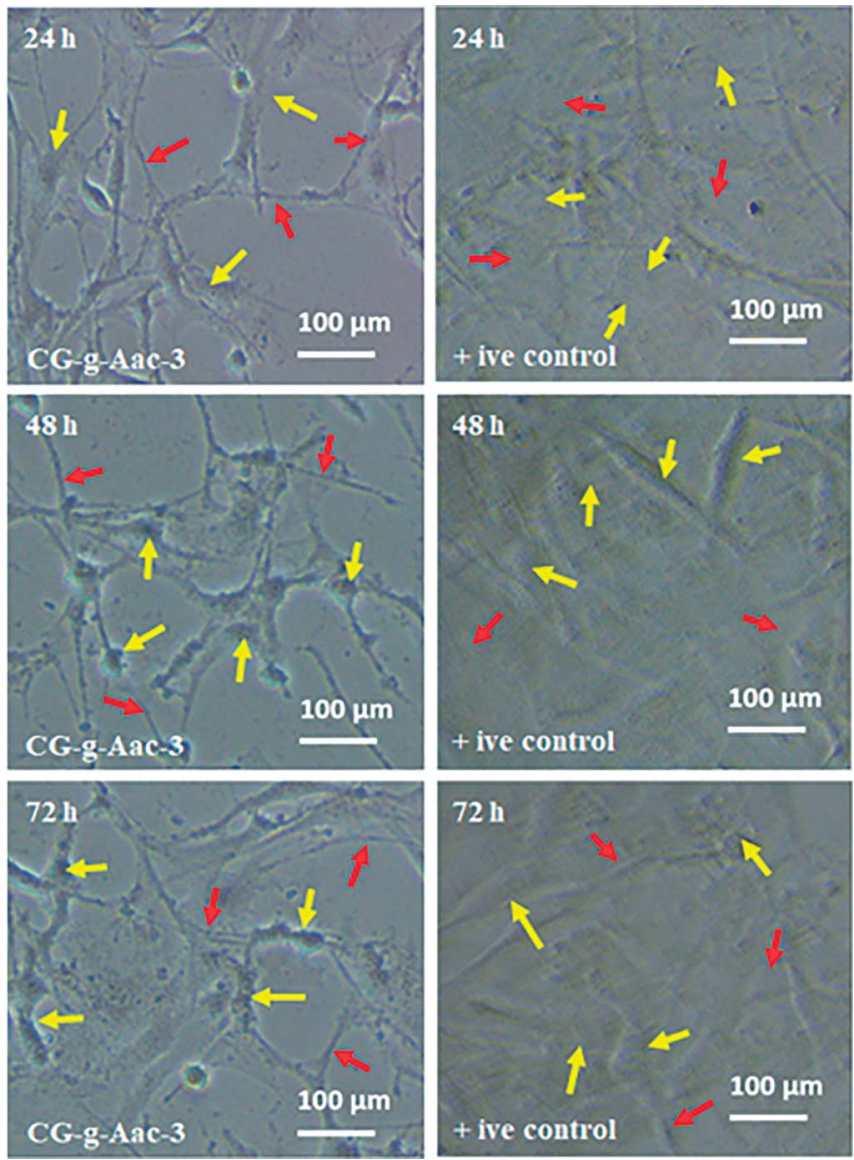

Fig. 9 Cell morphology of MC3T3-E1 against +ive control and all scaffold samples (CG-g-AAc1, CG- $g$-AAc2 and CG-g-AAc3) under standard in vitro conditions. The red arrows show thread-like morphology and the yellow arrows exhibits well-grown morphology of the cells.

The Royal Society of Chemistry apologises for these errors and any consequent inconvenience to authors and readers. 